\title{
Activities Reducing the Stress among Undergraduate Medical Students: The Students' Perception
}

\author{
Zakir Hassan', Ashraf Uddin Ahmed', Humayun Kabir Talukder ${ }^{3}$, Aliva Salmeen $^{4}$, Kazi Khairul Alam ${ }^{3}$, Hans V. Westerhoff $^{5,6,7}$, \\ Zahid Hassan ${ }^{8}$
}

\begin{abstract}
Most attention has been focused in recent years with respect to the issues of the medical students suffering from excess of stress during their studies, which may constrain their extent of learning, acquisition of knowledge, and consequently their academic performance. A cross-sectional descriptive study was conducted between July 2016 and June 2017 to explore the activities which helped to reduce the burden of stress among the undergraduate medical students of four government and two private medical colleges in Bangladesh. A self-administered semi-structured questionnaire was used to collect the data on the students' perception. A total of 1145 students included in this study of which $63 \%$ were female. The study revealed that the students' perceptions of stress were highest with respect to the existing policy concerning vacation/holiday $(87 \%)$, common room facilities (78\%), counselling service (64\%) and accommodation facilities (60\%). The most common coping strategies adopted by the students were discussing problems with family members and friends, gossiping with friends and using social media. Neither alcohol nor drug consumption was mentioned by the students as an effective stress reduction strategy. To generalize the findings, a further longitudinal study including prospective and multi-center focus group discussions along with quantitative research is recommended.
\end{abstract}

Keywords: Activities, stress, institutional initiatives, medical students, Bangladesh

\section{Introduction}

Stress is one of the most common and process-oriented obstacles to success of medical education globally (Gade et al., 2014). It often exerts a negative effect on academic performance, physical, and mental health of the students. And this may hinder later to their professional development and even in clinical practice (Rahman et al., 2015). Tired and

\footnotetext{
1. Army Headquarters, Medical Directorate, Dhaka Cantonment, Dhaka 1206, Bangladesh

2. Department of Community Medicine, Green Life Medical College, Dhaka 1205, Bangladesh

3. Center for Medical Education, Mohakhali, Dhaka 1212, Bangladesh

4. National Institute of Preventive and Social Medicine (NIPSOM), Mohakhali, Dhaka 1212, Bangladesh

5. Department of Molecular Cell Biology, Faculty of Science, Vrije Universiteit Amsterdam, the Netherlands, EU

6. Manchester Centre for Integrative Systems Biology (MCISB), School of Chemical Engineering and Analytical Sciences (SCEAS), the University of Manchester, Manchester, United Kingdom

6. Synthetic Systems Biology and Nuclear Organization, Swammerdam Institute for Life Sciences, University of Amsterdam, Amsterdam, the Netherlands, EU

7. Deptartment of Genetic Engineering and Biotechnology, Jagannath University, Dhaka 1100, Bangladesh
}

Address of correspondence:

Brg. Gen. Zakir Hassan

Army Headquarters, Medical Directorate, Dhaka Cantonment,

Dhaka 1206, Bangladesh

Email: zahid@geb.jnu.ac.bd tense doctors may not provide good-quality of care (Soliman, 2014). A more manageable, less stressed and more humane image of the profession should decrease the stress and its consequences(Mahajan, 2010).

Several studies have assessed both the perception of stress and coping up strategies among medical students (Al-Dubai et al., 2013, Nazeer and Sultana, 2014a). On the other hand, few studies done so far have managed to develop robust strategies to reduce the stress among undergraduate medical students (Eva et al., 2015, Sultana, 2014). In this study, we hypothesized that changes in the existing institutional facilities and students' activities could help to alleviate the stress among medical students. Therefore we first made a baseline survey of students' perception regarding existing institutional facilities and coping strategies of students. We did this for a single country Bangladesh. This survey suggests handles by which stress could be reduced. The effectiveness of these handles should be examined in followup studies where they are put in place.

\section{Materials and Methods}

A cross-sectional descriptive study was conducted between July 2016 and June 2017 among the undergraduate students of six (four from government and two from private) selected medical colleges of Bangladesh. A total of 1169 students from $2^{\text {nd }}$ to $5^{\text {th }}$ academic year were subjected to interview in this study. Students who were present at the time of data collection and willingly to participate into the study were enrolled.

A self-administered semi-structured questionnaire was used to collect data from the students adopting convenience sampling technique. Participants in this study were enrolled

Bangladesh Journal of Medical Education 2019;10(1):20-24. (C) 2019 Hassan et al., publisher and licensee Association for Medical Education. This is an Open Access article which permits unrestricted non-commercial use, provided the original work is properly cited. 
voluntarily. Questionnaires were given to the available students of each academic year just after the end of the lecture class. All the respondents were informed about the study objectives, their participation anonymity and research ethics. As the study was based on questionnaires, the medical colleges' authorities gave verbal consent to collect the data.

\section{Results}

There were 1169 enrolled initially to the survey, but only 1145 respondents returned the questionnaires; a response rate of $98 \%$. Of them, $63 \%$ (a total of 720 ) were female (Fig. 1).

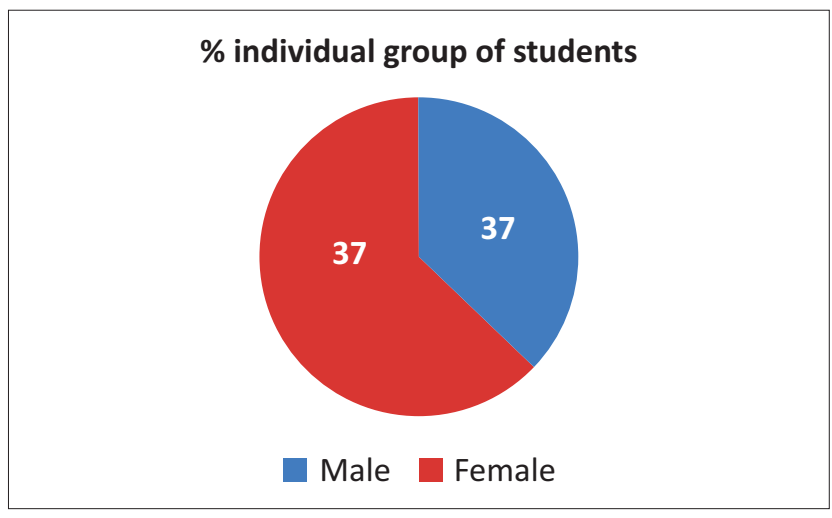

Fig. 1 Comparison (\%) of male and female respondents were from six selected medical colleges in Bangladesh.

The respondents were from $2^{\text {nd }}$ year to $5^{\text {th }}$ year (Fig. 2). Students enrolled from $3^{\text {rd }}$ year and $5^{\text {th }}$ year were almost similar $(27 \%)$, followed by $25 \%$ and $21 \%$ from $4^{\text {th }}$ year and $2^{\text {nd }}$ year respectively. Fig. 2 showed the academic year-wise distribution of male and female students in six different medical colleges of Bangladesh. Among the distribution, female respondents were nearly two-thirds of the total students.

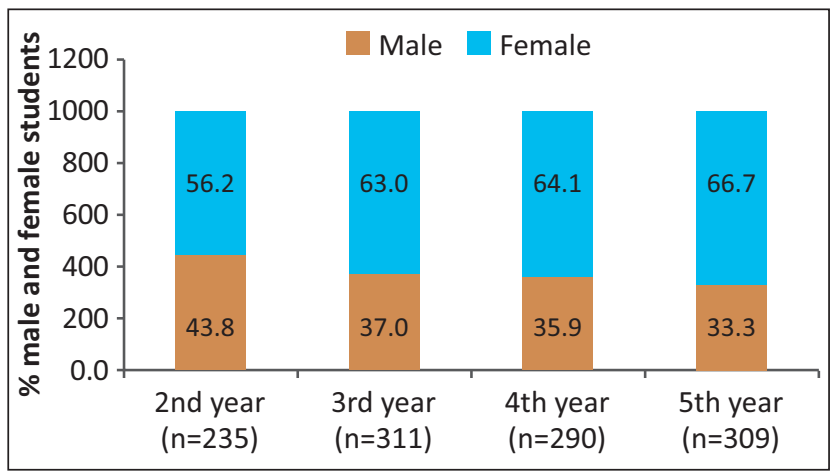

Fig.2 Distribution of the students by their gender and academic year in six different medical colleges.

The respondents' opinion about the existing facilities at the institutes is shown in Table 1. Among the respondents $(\mathrm{n}=$ 1145), nearly $57 \%$ opined that the institutes provide adequate library facilities, whereas $61 \%$ stated that indoor/outdoor game facilities were insufficient. Approximately $60 \%$ disputed about the current accommodation management. Almost four-fifths (78\%) of them reported the poor common room facilities to contribute to stress. When we looked for other factors, for example the duration of vacation/leave, $87 \%$ respondents expressed their view that vacation/holiday was insufficient for relaxing the stress. Almost two-thirds $(64 \%)$ pointed out that there were no effective counselling services for students. In fact, only 1124 students answered the question about the existing stipend facilities. Of them, $46 \%$ mentioned insufficiency of the institutional stipend as stress factor (Table 1).

Table 1. Delineation of the students' $(n=1145)$ opinion with the existing facilities at six selected medical colleges in Bangladesh.

\begin{tabular}{lccc}
\hline \multirow{2}{*}{ Types of statement } & Agree & NAND & Disagree \\
\cline { 2 - 4 } & $\mathbf{f ( \% )}$ & $\mathbf{f ( \% )}$ & $\mathbf{f ( \% )}$ \\
\hline Adequate library facilities & 647 & 91 & 407 \\
& $(56.51)$ & $(7.95)$ & $(35.55)$ \\
Sufficient indoor/outdoor & 351 & 93 & 701 \\
games facilities & $(30.66)$ & $(8.12)$ & $(61.22)$ \\
Sufficient vacation/leave & 119 & 32 & 994 \\
& $(10.39)$ & $(2.79)$ & $(86.81)$ \\
Stipend for insolvent students & 344 & 259 & 521 \\
(n=1124) & $(30.60)$ & $(23.04)$ & $(46.35)$ \\
Sufficient accommodation & 370 & 93 & 682 \\
& $(32.31)$ & $(8.12)$ & $(59.56)$ \\
Common room facilities & 195 & 62 & 888 \\
& $(17.03)$ & $(5.42)$ & $(77.55)$ \\
Effective student's counseling & 226 & 187 & 732 \\
service & $(19.74)$ & $(16.33)$ & $(63.94)$ \\
\hline
\end{tabular}

*Values from SA (strongly agree) and A (agree) were calculated together for describing the sum of values (\%) all over the text reported as 'agree'. Similar approaches were applied for sum of values (\%) calculated from DA (disagree) and SDA (strongly disagree) reported as 'disagree' parameter (please see SI for questionnaire score values).

The students' perception on which of their own activities helped to reduce their stress is shown in Table 2. Among the respondents $(\mathrm{n}=1145)$, more than $78 \%$ shared their problems with their family members and friends. Ninety percent relaxed while gossiping with friends and $80 \%$ of the students used social media to get rid of stress. We found that nearly $73 \%$ (out of 1137) engagement in social activities, for instance helping patients. Atleast, $86 \%$ respondents agreed that facilitating prayer/yoga/meditation might reduce the stress. Fewer than $10 \%$ of the respondents thought that smoking or taking alcohol/drugs alleviates their stress. Moreover, $62 \%$ respondents opposed to the idea that taking medicine could provide a way to relieve stress. 
Table 2. Distribution of students' $(\mathrm{n}=1145)$ response from six selected medical colleges which relates to their individual activities pursuing as a way for stress management/ stress reduction during their academic periods.

\begin{tabular}{lccc}
\hline Types of statement & Agree & NAND & Disagree \\
\cline { 2 - 4 } & $\mathbf{f ( \% )}$ & $\mathbf{f ( \% )}$ & $\mathbf{f ( \% )}$ \\
\hline Sharing problems with the & 894 & 98 & 153 \\
family members & $(78.08)$ & $(8.56)$ & $(13.36)$ \\
Sharing personal problem & 927 & 107 & 111 \\
with friends & $(80.96)$ & $(9.35)$ & $(9.69)$ \\
Getting relaxed by gossiping & 1023 & 62 & 60 \\
with friends & $(89.34)$ & $(5.41)$ & $(5.24)$ \\
Using social media to get & 921 & 101 & 123 \\
relax & $(80.44)$ & $(8.82)$ & $(10.74)$ \\
Involvement in social & 825 & 177 & 135 \\
activities (n= 1137) & $(72.56)$ & $(15.57)$ & $(11.87)$ \\
Offering prayer/meditation to & 980 & 87 & 78 \\
get rid of stress & $(85.59)$ & $(7.60)$ & $(6.81)$ \\
Medication & 250 & 186 & 709 \\
& $(21.83)$ & $(16.25)$ & $(61.92)$ \\
Smoking & 76 & 43 & 1026 \\
& $(6.64)$ & $(3.75)$ & $(89.61)$ \\
Addiction to alcohol/drug & 42 & 47 & 1056 \\
& $(3.67)$ & $(4.10)$ & $(92.23)$ \\
\hline
\end{tabular}

*Values from SA (strongly agree) and A (agree) were calculated together for describing the sum of values (\%) all over the text reported as 'agree'. Similar approaches were applied for sum of values (\%) calculated from DA (disagree) and SDA (strongly disagree) reported as 'disagree' parameter (please see SI for questionnaire score values).

\section{Discussion}

In this study, two types of factors were pointed out that affect the stress experienced by students, i.e. the environment provided to them and the activities they undertake. We did this for a specific country (Bangladesh) and a specific type of study (medical students). Some of the results (e.g. on alcohol and tobacco use) may be much different for other countries and studies, but others may be more general. The statistics of this study appears to be good, more than 1000 students presented with a questionnaire responded at a close to $100 \%$ rate. This by itself suggest that stress management during academic studies is and of concern to the students.

\section{How the students' environment affects stress levels}

Starting with what appears to be good, library facilities appear to help. In our study more than half of the students opined that their institute provided adequate library facilities (Table 1). Other studies students of all academic years showed that their students were quite stressed due to inadequate facilities in the library (Dhillon et al., 2006, Mahajan, 2010, Nazeer and Sultana, 2014a). We may conclude that library facilities may help in managing the stress of the students and that the particular institutions that we examined were doing OK here.

Perhaps not unexpectedly, the rebound is in the hostel facilities. Duly allotted and comfortable hostel accommodation may be one of the important factors to make the students less stressed (Table 1). Similar studies also reported that the most common source of stress among the students was their living condition in the hostel (Nazeer and Sultana, 2014a, Nazeer and Sultana, 2014b, Sreeramareddy et al., 2007). We suppose that hostel facilities were so incompatible with studying that students fled into the libraries for being able to study. In keeping with this, three quarters of the students felt that common room facilities were inadequate (Table 1). Also in previous studies students of all academic years were quite stressed due to inadequate recreational facilities (Mahajan, 2010, Nazeer and Sultana, 2014a, Shaikh et al., 2004). On the basis of our findings, we propose that medical students should be offered more opportunities for recreational facilities and better accommodations for studying, in order to minimize the stress. Not unexpectedly was that almost half the students stated that financial benefits were not provided by the institutions to the insolvent students. Other studies also reflected our findings that financial constraints in general were one of the common sources of stress among the students (Al-Dubai et al., 2013, Nazeer and Sultana, 2014a, Shaikh et al., 2004).

The study had hypothesized that the duration of vacation/holidays were another potential factor responsible for managing stress. The present study revealed that almost all students argued that the duration of vacation during the course is insufficient (Table 1). Other studies also supported our hypothesis that vacation and holidays were key factors responsible for managing stress '(Gade et al., 2014, Nazeer and Sultana, 2014a). It seems that the institutions could substantially help to relieve the stress by ensuring adequate leave to the students. Although this reduces teaching time, it may well be that the optimum for knowledge acquisition actually reside at a lower rather than higher offering of such knowledge.

Surprisingly and importantly because it appears to be something that is quite manageable, in this study more than half of the students felt that effective student counselling services were not prevailing in the institutions (Table 1). Counselling services could help make the students aware of stress and its management (Al-Dubai et al., 2013, Mahajan, 2010, Nazeer and Sultana).

How the students' activities affect stress levels

A great majority of the students reduce stress by talking with family and friends (Table 2), as had also been found by (Bukhsh et al., 2011, Eva et al., 2015, Nazeer and Sultana, 2014a, Shaikh et al., 2004). Nine out of ten students noted 
that students became relaxed by gossiping with friends (Table 2), confirming results obtained in Pakistan (Shaikh et al., 2004). Four out of five students expressed their opinion that students used social media to get relaxed (Table 2), in agreement with the previous finding that social media could help to reduce the stress '(Eva et al., 2015, Nazeer and Sultana, 2014a). Three quarters of the students stated that students alleviated stress by helping patients socially (Table 2), was consistent with the report by (Eva et al., 2015). It may not be unrelated to this that the great majority of the students noted that offering prayer/practice yoga/meditation could reduce the stress (Table 2). This finding agreed with the outcome of other studies (Eva et al., 2015, Gade et al., 2014, Shaikh et al., 2004, Nazeer and Sultana, 2014a).

Usage of alcohol, tobacco, and drugs were the common strategies to cope stresses in medical students in the United Kingdom (Ashton and Kamali, 1995), but not at all in this study. This indicates that for some issues there are vast differences between countries. It remains to be established whether this is actual and stable, or socially and culturally enforced.

\section{Recommendations}

Based on the overall findings of student perception, the following handles are suggested for reducing student stress better:

I. institutes should perhaps set up a monitoring system to identify the stressful condition of the students,

ii. the institute should provide adequate psychological, societal and academic counseling service for the students,

iii. preparatory leave mentioned in curriculum for each phase should be followed strictly and

iv. hostel accommodation and recreational facilities should be enhanced perhaps also with an eye of enabling studying at the hostel location.

In addition, then medical colleges should have a keen eye on how talking/ gossiping/ social-mediating with friends constitute a major way of stress reduction, and may create major facilities for such activities. These may not be libraries or hostels, but tea/coffee bars, students meeting points or movie theatres on campus. Proper facilities for private prayer and meditation should also help. Providing tobacco, drugs or medicines does not appear to be a priority. We note however that these are suggestions only.

\section{Conclusion}

The present cross-sectional descriptive study has been attempted to identify the potential factors contributing to reduce the stress among the students of six selected medical colleges of Bangladesh. This finding will help to improve our understanding of the causes and consequences of medical student stress, potential solutions. A double-blind study is needed to prove that any of these factors works independently of the others. Indeed, many of the factors mentioned may be confounded; students may gossip in libraries or vacation/leave does help against stress but is not properly managed. To generalize our findings in depth interviews, focused group discussion, large scale of quantitative study across national borders are recommended. Longitudinal follow ups of such studies to obtain the magnitude of the problem and to assess how it perpetrates into medical practicing should be useful.

\section{Acknowledgement}

Authors are much grateful to the students who participated in this study and express their heartfelt thanks to the principals of the selected six medical colleges of Bangladesh for their kind cooperation to conduct the study.

\section{Conflict of interest}

The authors declare no conflict of interest.

\section{References}

1. Al-Dubai, S. A. R., Al-Naggar, R. A., Alshagga, M.A. \& Rampal, K. G. 2013. Stress and coping strategies of students in a medical faculty in Malaysia. Malays J Med Sci, 57-64.

2. Ashton, C. \& Kamali, F. 1995. Personality, lifestyles, alcohol and drug consumption in a sample of British medical students. Medical Education, 29, 187-192.

3. Bukhsh, Q., Shahzad, A. \& Nisa, M. 2011. A study of learning stress and stress management strategies of the students of postgraduate level: a case study of Islamia University of Bahawalpur, Pakistan. Procedia Soc Behav Sci, 30, 182-186.

4. Dhillon, J., Mcgowan, M. \& Wang, H. 2006. What do we mean by student support? Staff and students perspectives of the provision and effectiveness of support for students. University of Wolverhampton, Learning and Teaching Projects 2005/2006 1-7.

5. Eva, E. O., Islam, M. Z., Mosaddek, A. S. M., Rahman, M. F., Rozario, R. J., Iftekhar, A. M. H., Ahmed, T. S., Jahan, I., Abubakar, A. R. \& Dali, W. P. E. W. 2015. Prevalence of stress among medical students: a comparative study between public and private medical schools in Bangladesh. BMC Res Notes, 8, 327-333.

6. Gade, S., Chari, S. \& Gupta, M. 2014. Perceived stress among medical students: To identify its sources and coping strategies. Arch Med Health Sci, 2, 80-86. 
7. Mahajan, A. S. 2010. Stress in medical education: a global issue or much ado about nothing specific? Southeast Asian J MedEduc, 4, 9-13.

8. Nazeer, M. \& Sultana 2014a. Stress and it's Coping Strategies in Medical Students. Sch J App Med Sci, 2, 3111-3117.

9. Nazeer, M. \& Sultana, R. 2014b. Stress in Medical Education and its Management. Int J Sci Res, 3, 355359.

10. Rahman, N. I. A., Ismail, S., Ali, R. M., Alattraqchi, A. G., Dali, W., Umar, B. U., Nadiger, H. A. \& Haque, M. 2015. Stress among first batch of MBBS students of Faculty of Medicine and Health Sciences, Universiti Sultan Zainal Abidin, Malaysia: when final professional examination is knocking the door. Int Med J, 22, 254259.
11. Shaikh, B. T., Kahloon, A., Kazmi, M., Khalid, H., Nawaz, K., Khan, N. \& Khan, S. 2004. Students, stress and coping strategies: a case of Pakistani medical school. Educ Health (Abingdon), 17, 346-353.

12. Soliman, M. 2014. Perception of stress and coping strategies by medical students at King Saud University, Riyadh, Saudi Arabia. J Taibah Univ Med Sci, 9, 30-35.

13. Sreeramareddy, C. T., Shankar, P. R., Binu, V., Mukhopadhyay, C., Ray, B. \& Menezes, R. G. 2007. Psychological morbidity, sources of stress and coping strategies among undergraduate medical students of Nepal. BMC MedEdu, 7 (26).

14. Sultana, N. 2014. Stress and depression among undergraduate medical students of Bangladesh. Bangladesh J MedEdu, 2, 6-9. 